\title{
A Novel Method for Evaluating Diversity of Stand Structure Based on Relationship of Adjacent Trees
}

\section{ZHONGHUA ZHAO ( $\nabla$ zhh-zhao@163.com )}

Universita degli Studi di Palermo Dipartimento di Scienze Agrarie e Forestali https://orcid.org/00000003-3239-0675

\section{Gongqiao Zhang}

Chinese Academy of Forestry Research Institute of Forestry

\section{Wenzhen Liu}

Xiaolongshan research institute of forestry

\section{Gangying Hui}

Research Institute of Forestry,CAF

Ganggang Zhang

Research institute of forestry,CAF

\section{Aiming Yang}

Research institute of forestry, CAF

\section{Research}

Keywords: relationship of adjacent trees, spatial structural parameters, size differentiation, mingling, uniform angle index, structural unit types, stand structural diversity index

Posted Date: March 22nd, 2021

DOl: https://doi.org/10.21203/rs.3.rs-331356/v1

License: (c) (1) This work is licensed under a Creative Commons Attribution 4.0 International License. Read Full License 


\section{trees}

Zhonghua Zhao ${ }^{1}$, Gongqiao Zhang ${ }^{1}$, Wenzhen Liu ${ }^{2}$, Gangying Hui ${ }^{1}$, Ganggang Zhang $^{1}$, Aiming Yang ${ }^{1}$

Author contact information:

Zhonghua, Zhao: Beijing 1958 box, Research Institute of Forestry, CAF, Beijing,100091;

E-mail: zhh-zhao@163.com;

Gongqiao, Zhang: Beijing 1958 box, Research Institute of Forestry, CAF, Beijing,100091;

E-mail: zhanggongqiao@126.com;

Wenzhen,Liu: Mapaoquan Road No.60, Maiji District, Tianshui City, Gansu Province,China, 741020;E-mail: liu_wenzhen@163.com

Ganggang,Zhang: Beijing 1958 box, Research Institute of Forestry, CAF, Beijing,100091;

E-mail: zg201394@163.com;

Aiming,Yang: Beijing 1958 box, Research Institute of Forestry, CAF, Beijing,100091; Email:691716340@qq.com;

Corresponding author: Gangying, Hui, Beijing 1958 box, Research Institute of Forestry, CAF, Beijing,100091; Tel: +8601062888793; Fax:+8601062872015; E-mail: hui@caf.ac.cn. 


\section{Abstract:}

Background: Improving the diversity and complexity of stand structure is the basis for maintaining and increasing forest ecosystem biodiversity. Measures of stand structural diversity is important for predicting stand growth and evaluating forest management activities. Based on the relationship of adjacent trees, we present a new method for the quantitative analysis of stand structure diversity that allows comparison of stand structural heterogeneity between different stands and forest types and to quantify the impact of forest management on structural diversity.

Method: The diversity of structural unit types was defined and then we derive a new index of forest structural diversity $\left(S^{\prime}{ }_{D}\right)$ according to the additivity principle of Shannon-Weiner index. The effectiveness and sensitivity to management were verified by sixteen field survey samples in different locations and six different simulated management datasets based on Pinus koraiensis broad-leaved forest survey sample.

Results: (1) The mountain rainforest in Hainan had the highest $S_{D}^{\prime}$ value at 5.287, followed by broad-leaved Korean pine forest in Jiaohe (2), Jiaohe (1) and oak broadleaved mixed natural forest in Xiaolongshan (2), with values of 5.144, 5.014 and 5.006, respectively. The $S^{\prime}{ }_{D}$ values of plantations and natural pure forest were lower. (2) Different thinning methods and intensities reduced $S^{\prime}{ }_{D}$ compared with no treatment and magnitude of the with the differences were greater as thinning intensity increased. The $S^{\prime}{ }_{D}$ value of thinning from above decreased more than thinning from below at the same thinning intensity.

Conclusion: The $S^{\prime}{ }_{D}$ well describes differences in stand structural diversity of different forest types and allows comparison of stand structural heterogeneity. It is also sensitive to forest management activities and to quantify the impact of forest management on structural diversity. The application of this new index $S^{\prime}{ }_{D}$ could greatly facilitate forest 
management and monitoring.

53 Key words: relationship of adjacent trees; spatial structural parameters; size differentiation;

54 mingling; uniform angle index; structural unit types; stand structural diversity index.

55 


\section{Introduction}

Forest structure is an important feature of forests and reflects the connection among individual trees (structural elements) and their attributes (type, size, distribution). Stand structure are a comprehensive reflection of forest development processes, such as regeneration patterns, competition, natural thinning and disturbance (Lei \& Tang, 2002). Additionally, stand structure plays an important role in and is affected from management activities such as harvesting, thinning, weed control and planting (O'Hara, 1998). Increasing the diversity and complexity of stand structure is the foundation and an effective approach for maintaining and increasing forest ecosystem biodiversity (Franklin, et al., 2002; Lei et al., 2009; Valbuena et al., 2012).

Stand structure diversity is not only related to species richness and size distribution in the community (Buongiorno et al., 1994), but also depends on the horizontal distribution of individual trees (MacArthur \& MacArthur, 1961). Measures of stand structural diversity is important for predicting stand growth (Staudhammer and LeMay, 2001) and forest management activities (O'Hara, 1998). The methods of measuring stand structure diversity can be roughly divided into three categories according to the stand structure attributes, types of measurement and mathematical framework. The first type describes biodiversity using the standard deviation or the coefficient of variation, such as the composition diversity of the basal area (Holland, et al., 1994; Buongiorno, et al., 1994; Volin, et al., 1996), standard deviation of diameter at breast height (Spies \& Franklin, 1991; Zenner, 2000; Neumann \& Starlinger, 2001), tree height standard deviation (Zenner, 2000; Svensson \& Jeglum; 2001), foliage height diversity (MacArthur et al., 1961) or dead standing (fallen) wood diversity (Dewalt, et al., 2003; Bachofen and Zingg, 2001; Svensson \& Jeglum, 2001; Sullivan, 2001). However, these methods only quantify single structural attributes at a time. And it has often been argued that they fall short to fully assess stand structural diversity (Gove et al., 1995; Buongiorno et al., 1994). The second category is 
based on accumulating structural attributes using weights. A set of stand structure attributes are selected and assigned different scores or weights according to the importance of the structural attributes. The stand structure attributes are combined to express the stand structure diversity using a sum or average of the weights. For example, Barnett (1978) and Newsome and Catling (1979) assigned values according to the coverage of different levels to evaluate the diversity of stand structure. Van Den Meersschaut and Vandekerkhove (1998) selected 18 indicators, assigned different weights and summed up the weights to describe the biodiversity of Belgian forests. The third category is based on the interaction of structural attributes that combine the structural attributes of the stand with a nonlinear method, such as the structural complexity index (HC) proposed by Holdridge (1967), which combined tree height, basal area, density and the number of species in the upper layer to evaluate stand diversity. For example, the stand diversity index (SD) by Jaehne and Dohrenbusch (1997) multiplied species composition, diameter, distance between the trees and variation of crowns to express the stand structure diversity. Although some progress has been made in the evaluation of stand structural diversity, these indicators are still considered incomplete(Franklin et al., 2002; Ferris and Humphrey, 1999; Noss, 1990), because there is still a lack of structural diversity indicators that can be easily applied to forest management through sampling and a finite set of measurements, and can be used to assess current stand conditions and prescribe desired treatment outcomes evaluate the current stand status and management effect.

Many methods are available for describing tree distribution patterns but few contain tree position information (Ripley, 1977; Stoyan, 2000; Illian et al., 2008; Wiegand \& Moloney, 2013). Zenner (2000) proposed the Structural Complexity Index (SCI), which combines tree height and spatial location. The SCI quantifies the relationship between tree position and tree height and is very sensitive to density changes at high stand density. However, SCI requires coordinates and height of each individual tree. Furthermore, SCI 
values are only comparable when stand density is similar. In recent years, the methods of mark point patterns or mark second-order characteristics were used to describe the characteristics of forest tree attributes changing with scale (Gavrikov \& Stoyan, 1995; Pommerening et al., 2011; Wiegand \& Moloney, 2013; Hui and Pommerening, 2014; Pommerening and Sarkka, 2013). However, pre-requisite for these methods are coordinates and the process of calculation is very complex which requires using specific codes or software. Compared to the large number of literatures on point processes, suitable structure diversity indicators which include the horizontal distribution information without relying on coordinates are scarce.

Forests are three-dimensional systems whose biophysical structure plays a major role in ecosystem functioning and diversity (Kuuluvainen et al. 1996; Spies 1998). Maintaining and improving the complexity and diversity of forest ecosystem structure has become an important target of sustainable forest management. Gadow (1999) and Pommerening $(2002,2006)$ considered that forest structural diversity can be described and characterized by the diversity of tree species, location and size differentiation at the stand level. However, the existing indicators of stand structure diversity rarely include tree species, location and size differentiation information at the same time. In recent years, structural parameters based on a reference tree and its nearest neighbors, designated as structural unit (refer to table 1 for a definition) has been widely used in stand structure analysis and regulation of forest structure (Albert \& Gadow, 1998; Neumann \& Starlinger, 2001; Kint et al., 2003; Gadow \& Hui, 2002; Hui \& Albert, 2004; Graz, 2004; Hui, et al., 2011; Li, et al., 2012; Li, et al., 2014; Zhao, et al., 2015). Three spatial structure parameters can depict small-scale variation in tree species (mingling), size differentiation (differentiation) and distribution patterns (uniform angle index), respectively. These three parameters are independent of each other and have the same range of values. According to these important features, joint probability distributions method have been put forward and applied to analysis forest 
spatial structure characteristics and selected of cutting trees in the broad-leaved Korean pine forest of Northeast and pine-oak mixed forest in the Xiaolong Mountains, China (Li, et al., 2012,2014; Zhang, et al., 2019). The multi parameters distribution method provided more abundant and intuitive effective information than the single parameter and can be used to improve forest structure (Hui, et al., 2019; Zhang, et al., 2019). It provides a constructive reference for forest management to guide the improvement of stand structure diversity.

As mentioned above, the currently available methods to describe biodiversity have limitations. The neighborhood-based structural parameters as one method to analyze biodiversity are used separately to describe stand structure thus far. Therefore, it is the goal of this study to make use of the structural units' attributes by combining them to a single biodiversity index. This newly derived index shall overcome previous limitations. The proposed properties of the new index are to (1) allow comparisons of structural heterogeneity between different forest stands and forest types and (2) to quantify the effect of forest management on structural diversity. In this study we will evaluate the new index based on a dataset which consist of field measurements with known tree coordinates from different geographical regions. Furthermore, we will test the sensitivity of the new stand structure diversity index to stand structure change based on an artificial dataset of simulated management activities.

\section{Methods}

\section{Neighborhood-based structural parameters}

Gadow (1993) and Hui et al. $(1998,1999,2003)$ define a structural unit as a group of $n$ nearest neighbors to a reference tree $i$ (Fig. 1; cf. table 1). Within the structural unit the neighborhood-based structural parameters are mingling $\left(M_{i}\right)$, size differentiation $\left(U_{i}\right)$ and uniform angle index $\left(W_{i}\right)$. These parameters have proven useful for analyzing the spatial structure of mixed forests (Hui et al. 1998, 2019; Graz 2004, 2006; Pommerening 2006). 
Mingling is used to express the segregation of different species in multispecies forests and is defined as the proportion of the $n$ nearest neighbors that are different species from the reference tree $i$ (Gadow, 1993; Füldner, 1995; Hui et al., 2011). The size differentiation explains the differentiation between a reference tree and its nearest neighbors in the form of a proportion and is defined as the proportion of the $n$ nearest neighbors in the structural unit that have a smaller dimension (e.g. dbh, height, crown width etc.) than the reference tree $i$ (Hui et al., 1998; Aguirre et al., 2003). The uniform angle index $\left(W_{i}\right)$ describes the degree of regularity in the spatial distribution of $n$ trees that are nearest to a reference tree $i$ (Hui et al. 1998; Gadow et al., 1998; Aguirre et al., 2003; Hui et al., 2011) and is defined as the proportion of the smaller angle $\alpha$, which is composed of a reference tree with two adjacent nearest trees, is less than the standard angle $\alpha_{0}\left(72^{\circ}\right)$ (Hui et al. 1998, 2002; Aguirre et al. 2003). The values of the three spatial structure parameters have the same values in set $\{0.0,0.25,0.5,0.75,1.0\}$. According to the definition of the three spatial structure parameters, we can express them by a uniform formula as follows:

$$
\omega_{i}=\frac{1}{n} \sum_{j=1}^{n} v_{j}
$$

where $v_{j}$ is a discrete variable with value $v_{j} \in\{0,1\}$ and its meaning is related to the specific structure parameter and $n$ is the number of nearest trees in the spatial structural unit. We take $n$ as 4 in this study because it has been proven that four is the most appropriate number for assessing tree distribution patterns, depicting species segregation, and reflecting dominance (Albert 1999; Hui \& Hu 2001) while still being cost effective (Wang et al., 2015). The value of $\omega_{i}$ can take on five possible values, and the meaning of each parameter value is shown in Figure 2.

\section{Diversity of the structural unit types}

According to the uniform formula of neighborhood-based parameters [eq. 1], any structural unit isochronously contains three factors (distribution pattern, tree species and 
size). The different combinations of each parameter's values can be regard as different structural unit types (cf. table 1), just like different species in a community. Their possible value combinations may be $C_{5}^{1} \times C_{5}^{1} \times C_{5}^{1}=125$ cases when only considering the different value combinations of the three parameters. The diversity within a structural unit can be described by these different combinations. As we want to use the structural unit type as a part in our new structural biodiversity index by calculating the Shannon-Weiner index (Shannon and Weaver, 1949) on this basis, we need to consider that the same mingling value may have different structural unit types due to the different tree species number in the structural unit. Table 2 illustrates this phenomenon. The number of tree species in the structural unit is 1 and 2 when the mingling value is 0 and 0.25 , respectively; when the value of the mingling is greater than 0.25 , the number of tree species may be different despite having the same mingling value for the structural unit. Therefore, according to the number of tree species in the structural unit, the possible value combinations should be $\left(C_{1}^{1}+C_{1}^{1}+C_{2}^{1}+C_{3}^{1}+C_{4}^{1}\right) \times C_{5}^{1} \times C_{5}^{1}=275$ cases, i.e. 275 possible structural unit types.

According to the above analysis, we present a method for expressing the diversity of the structural unit types based on the Shannon-Weiner index (Shannon and Weaver, 1949) (formula 2).

$$
D^{\prime}{ }_{U}=-\sum_{i=1}^{N} u_{i} \ln u_{i}
$$

where $D^{\prime}{ }_{U}$ is the diversity of structural unit types, $u_{i}$ is the proportion of the $i-t h$ structural unit type in all combination cases, and $N$ is the number of structural unit types and its maximum number is 275 . When there is only one structural unit type $(N=1)$ in the forest, $D^{\prime}{ }_{U}$ has a minimum value of zero. The more structural unit types and the more uniform the proportions, the greater the value of $D^{\prime}{ }_{U}$ The maximum value of $D^{\prime}{ }_{U}$ 
As mentioned above, $D^{\prime}{ }_{U}$ describes the diversity of the structural unit types and it is a very important aspect of the diversity of stand structure that reflects the diversity of the spatial distribution, species segregation and size differentiation of the $n$ nearest trees to reference tree $i$ in the structural unit. On the other hand, the total number of species in a stand and size differentiation of reference trees are also important aspect of the diversity of stand structure, because of the diversity of structural unit types only considered the tree species difference and relative tree size of the five trees in the structural units, so we need to consider tree species and size variation of forest stand when we describe the diversity of stand structure. The species diversity of reference trees in a stand is also described by the proportion of stems and the Shannon-Weiner index. The tree size variation (diameter, tree height or crown) in a stand, on the other hand, can be expressed by the coefficient of variation $(C V)$ which can be calculated as follows:

$$
C V=\sigma / \mu
$$

221 where $\sigma$ is the standard deviation of the individual tree size variation and $\mu$ is the mean value of individual tree size variation. The larger the value of $C V$, the greater the variation of differentiation of the individual trees in stand. Both, the Shannon-Weiner index on tree species diversity and $C V$ can be calculated based on the sampled trees, i.e. the reference tree $i$ and its $n$ nearest neighbors of all structural units in a forest stand.

$$
H^{\prime}(A B)=H^{\prime}(A)+H^{\prime}(B)
$$


In formula $4, H^{\prime}(A B)$ is the diversity of a community, $H^{\prime}(A)$ and $H^{\prime}(B)$ are the

diversities of different classifications of the same community, respectively. In our study, $H^{\prime}(A)$ is the diversity of tree species and it is represented by $H^{\prime}$ in formula $5, H^{\prime}(B)$ is

232 diversity of structural unit types and it is represented by $D^{\prime}{ }_{U}$.

$$
S^{\prime}{ }_{D}=C V \cdot\left(H^{\prime}+D^{\prime}{ }_{U}\right)=-C V \cdot\left(\sum_{j=1}^{S} p_{j} \ln p_{j}+\sum_{i=1}^{N} u_{i} \ln u_{i}\right)
$$

where $S^{\prime}{ }_{D}$ is the structural diversity index (cf. table 1) based on the neighborhood-based parameters, $H^{\prime}$ is the diversity of tree species, $S$ is the number of tree species in the stand, $p_{i}$ is the proportion of the $j$-th tree species in the stand; and $D^{\prime}{ }_{U}$ is the diversity of structural unit types (Formula 2), $N$ is the number of structural unit types and $u_{i}$ is the proportion of the $i$-th structural unit types in the stand. $C V$ is the coefficient of variation of the individual size. The value of $S^{\prime}{ }_{D}$, thus, is determined by the diversity of tree species, diversity of structural unit types and variation of the individual tree dimensions in the stand. If there is only one tree species in the stand, the diversity of structural unit types and variation of the individual size reflects the diversity of the stand structure.

\section{Data used and method of analysis}

Tree measurements from field plots in China, Germany, Poland, Myanmar and South Africa were analysed to evaluate the feasibility and usefulness of the structural diversity index. In these plots, the species and diameter at breast height (DBH) of every tree with a $\mathrm{DBH}$ greater than $5 \mathrm{~cm}$ was recorded. For more details and geographical location of sample plots, see Table 3 and the appendix. In addition, a variety of simulated thinning data based on field measurements were used to analyse the sensitivity to stand structure changes of the new structural diversity index.

\section{Measured Field Data}


provinces, are listed in the first eleven rows in Table 3. Two plots from the Beijing experiment are in Jiulongshan in western Beijing and Yiheyuanhou in northwestern Beijing. The Inner Mongolia experiments are in the Pinus sylvestris var. mongolica national nature reserve of Honghuerji, and they are natural pure forest. Two Jilin experiment represent selectively logged temperate forest. The three Gansu experiments are in the Xiaolongshan forest region, which represent broad-leaved deciduous forest in the transition area from the warm temperate zone to the northern subtropical zone. The Hainan experiment is in the Jianfengling nature reserve and is a typical virgin tropical forest.

The data from other countries are listed in rows twelve to sixteen in Table 3. The research plot Lensabn is in a forest near the town of Lensabn in northern Germany (Gadow et al., 2005). The Walsdorf data are from a management demonstration site in the German state of Rhineland-Palatinate. Manderscheid is a temperate, deciduous forest located in the West German state of Rhineland-Palatinate (Uria-Diez \& Pommerening, 2017). The Bialowieza forest stretches from eastern Poland across the border to western Belorussia (Pommerening \& Murphy, 2004). The Knysna research plot is part of the "French Volume Curve" (FVC) experimental area in the evergreen forests of the Southern Cape Region of South Africa (Kempka and Gadow, 1998). The Sinthwat research forest, which is situated near the Sinthwat village in the Paunglaung watershed of Myanmar, has been classified as a tropical mixed deciduous forest (Zin, 2005).

\section{Simulated thinning Data}

Simulated thinning plots were used to describe the changes of stand structure diversity after management. The purpose of including the simulated datasets was to test the sensitivity of the new structural diversity index to stand structure changes. Simulated thinning methods include simulated thinning from above and below and thinning intensity was $10 \%, 20 \%$ and $40 \%$ of stem number, respectively. For simulated thinning from above, the trees were removed from larger DBH to smaller DBH according to the corresponding 
intensity, while for simulated thinning from below, the trees were removed from smaller DBH to larger DBH according to the corresponding intensity. Based on the data of Jiaohe, Jinlin (2), and according to the above simulation thinning design method, a total of 6 new plots (Jiaohe, Jinlin (2) after thinning; Table 5) were generated for analysis.

Data analysis

$C V, D^{\prime}{ }_{U}, \quad H^{\prime}$ and $S^{\prime}{ }_{D}$ were calculated for each plot. The $\mathrm{DBH}$ was used for size differentiation. All data were calculated by $\mathrm{R}$ code written for calculation of stand diversity and forest spatial structure analysis. To eliminate the edge effect, a buffer of $3 \mathrm{~m}$ was set if the sample plot area is less than 1 hectare and a buffer zone of $5 \mathrm{~m}$ be set if the sample plot area is equal or greater than 1 hectare.

\section{Results}

\section{Stand characteristics and spatial pattern of field plots}

The plots we analyzed in this study covered different forest types from cold temperate natural pure forest to tropical montane rainforest, including several plantations (table 3). Tree densities in the 16 plots varied greatly from 374 trees per hectare in Sinthwat (plot 16) to 2331 in Jiulongshan (plot 7). Accordingly, the basal area per hectare ranged from $20.3 \mathrm{~m}^{2}$ $84.09 \mathrm{~m}^{2}$. In terms of the number of tree species in the plots, the number of tree species decreased with increasing latitude from tropical montane rainforest (Jianfengling, plot 1) to cold temperate natural pure forest (Honghuaerji, plot 9 and plot 10), and the number of tree species ranged from 1 to 84 in the plots. Mean mingling $\bar{M}$ was highest in Jianfengling, plot 1 (0.963), where the number of tree species was also highest (84). $\bar{M}$ was 0 in a natural pure forest (Honghuaerji, plot 9 and plot 10) and a Pinus bungeana plantation (Yiheyuanhou, plot 8), where only one tree species was in the plot. According to the test method of mean uniform angle index $\bar{W}$ (Zhao et al., 2014), three kinds of distribution patterns can be identified: uniform distribution patterns, including Jiulongshan (plot 7), 
Honghuaerji (plot 9 and plot 10), Yiheyuanhou (plot 8), Manderscheid (plot 12) and Walsdorf (plot 13), a slight cluster distribution, including Jianfengling (plot 1), Xiaolongshan (plot 6), and Bialowieza (plot 15), and all the other plots show random distribution pattern.

\section{Species diversity, size differentiation and structural unit types}

The data in Table 4 show the characteristics of the plot core area. The highest $H^{\prime}$ was in the mountain rainforest in Hainan, China (3.851), followed by the tropical mixed deciduous forest of Sinthwat, Myanmar (3.331). $H^{\prime}$ was zero for the Pinus sylvestris var. mongolica natural forest (plot 9 and plot 10) and Pinus bungeana plantation (plot 8) because there was only one species in those plots. The coefficient of variation of dbh $(C V)$ of different forest plots varied greatly. The largest $C V$ was Bialowieza, plot 15 (0.866), followed by that of Lensabn, plot 11 (0.751). The smallest $C V$ was 0.165 in the Pinus bungeana plantation in Beijing (plot 8). In terms of the number of structural unit types in the plots, the numbers were between 20 in Yiheyuanhou, plot 8, and 167 in Jiaobe (2), plot 3. There is obviously a trend that the structural unit types of mixed forest were higher than pure forest. The diversity of structure units in table 4 show that the value of $D^{\prime}{ }_{U}$ ranged from 2.585 in Honghuaerji, China (plot 9), to 4.726 in Xiaolongshan (3), China (plot 6), their numbers of structural unit types were 24 and 150, respectively. The highest and lowest numbers of structural unit type in 16 plots were 167 in Jiaohe (2), China (plot 3) and 20 in Yiheyuanbou, China (plot 8), and their value of ${D^{\prime}}_{U}$ were 4.645 and 2.604, respectively. These results show that the diversity of structural unit types not only related to the richness of structural unit types, but also to the uniformity of distribution of structural unit types.

\section{Stand structural diversity index $\left(S^{\prime}{ }_{D}\right)$}

In terms of the structural diversity index $S^{\prime}{ }_{D}$ table 4 the mountain rainforest in Hainan (plot 1) had the highest value at 5.287, followed by broad-leaved Korean pine forest 
in Jiaohe (2), plot 3, broad-leaved Korean pine forest in Jiaohe (1), plot 2, and oak broadleaved mixed natural forest in Xiaolongshan (2), plot 5, with values of 5.144, 5.014 and 5.006, respectively (cf. table. 4). Among all plots, the $S^{\prime}{ }_{D}$ values of plantations and natural pure forest were lower, and the lowest was 0.430 in the Pinus bungeana plantation (plot 8). Interestingly, the number and diversity of structural unit type of Hainan mountain rainforest (plot 1) were relatively lower, the main reason was that the structural unit type was dominated by the value of mingling equal to 1 , however, this stand had the highest interesting result is the stand structure diversity of Bialowieza, Poland (plot 15). In this stand, there were only 5 tree species, and the value of $H^{\prime}$ was only 1.020; however, its value of which led to its stand structural diversity $\left(S^{\prime}{ }_{D}\right)$ being higher than those of Sinthwat, Myanmar(plot 16), Knysna, South Africa (plot 14), Lensahn, Germany (plot 11), Xiaolongshan (1) and Xiaolongshan (3) (plot 4 and plot 6), and Jiulongshan (1) (plot 7), China, despite the higher number and diversity of tree species in these plots. In addition, two natural pure forest of Pinus sylvestris var. mongolica had the same tree species number and structural unit types, but they had different stand structure diversity due to size differentiation and diversity of structural unit types.

\section{Sensitivity analysis of stand structural diversity index to management} activities

The results of simulated thinning of different intensities and different forest layers of Pinus koraiensis broad-leaved forest in Jiaohe, Jilin (2), China were listed in Table 5. The results showed that the thinning had almost no obvious effect on the overall tree distribution pattern but had a significant impact on mingling, size differentiation and number of tree species of the forest. The number of tree species was reduced from 20 to 
16 after thinning, while the mean mingling and $H^{\prime}$ was increased after thinning from below. The size differentiation clearly decreased by reducing the coefficient of variation after the thinning especially after the thinning from above. The thinning from above tends to increase the structural unit types, while the thinning from below tends to be the opposite. The change in diversity of the structural unit type $\left(D^{\prime}{ }_{U}\right)$ is in accordance with the number of structural unit types. The value of stand structural diversity $\left(S^{\prime}{ }_{D}\right)$ of different thinning method and intensity have obviously decreased after thinning compared with unmanaged treatment, and their decreasing range increased with the thinning intensity. The value of $S^{\prime}{ }_{D}$ were 5.144 before thinning. After thinning from above with $10 \%, 20 \%$ and $40 \%$ intensity, the value was $3.578,2.895$ and 1.914 , respectively. In addition, the value of $S^{\prime}{ }_{D}$ of thinning from above decreased more than thinning from below at the same thinning intensity. For example, the value of ${S^{\prime}}_{D}$ decreased from 5.144 to 3.578 and 4.856 after thinning from above and below at thinning intensity, respectively. These results suggested that the structural diversity index $S^{\prime}{ }_{D}$ was very sensitive to changes of the stand structure. What needs to be explained here is that we are not evaluating the advantages and disadvantages of the thinning methods but emphasizing the sensitivity of the new stand structure diversity index to management activities.

\section{Discussion}

A measure of stand structural diversity is intuitively appealing if it can be used to compare the diversity across different ecosystems, not only in terms of the mere number of tree species but also considering size differences and individual tree distribution. In this study, by combining tree species diversity, size differences and structure unit type diversity and using the Shannon-Weiner diversity model, we can describe the diversity of stand structure. The test results of 16 forest stands indicated that the new structural diversity index $\left(S^{\prime}{ }_{D}\right)$ moves far beyond the tree species diversity index with increasing values from 
cold zone to tropical zone according to the number of tree species. For example, we compare the two plots in Jiaohe (plot 2 and plot 3) and the plot in Bialowieza (plot 15), which are all located in the cold temperate zone, to the plots Gansu (plot 4, plot 5 and plot 6) and Myanmar (plot 16) being located in the transition from temperate zone to subtropical zone and tropical zone. While Jiaobe and Bialowieza consist of only 18 and 5 tree species, respectively, their structural diversity index value is higher than that in Gansu and Myanmar with 30 to 56 tree species. This is mainly due to the higher number and diversity of structural unit type and the size differentiation of individual trees in plots. Another reason for Bialowieza (plot 15) is that the stand was managed according to the principles of continuous cover forestry (Pommerening \& Murphy, 2004) which increased the diversity of structural unit types and coefficient of variation of $\mathrm{DBH}$. In addition, the new stand structure diversity index can not only evaluate the structural diversity of mixed forests but can also be used to evaluate the structural diversity of artificial pure forests. This is a clear advantage over the classical Shannon-Weiner index because Shannon-Weiner index cannot be used to evaluate diversity of pure forest. The difference in structure between pure forests was mainly due to the size differentiation and distribution of individual trees. The results for three pure forests (Yiheyuanhou (2), Honghuaerji (1) and Honghuaerji (2)) indicated that the structural diversity of natural monocultural forests is higher than that of artificially planted pure forests because the individuals have a greater size differentiation and a relatively irregular distribution.

Thinning from above or below are traditional methods of forest operation, however, typical primary concerns in forestry are the amount of timber obtained from selective felling (Mäkinen and Isomäki, 2004), growth increments (Cassidy et al., 2012), non-timber forest products (Bonet et al., 2012), and so on. The structural diversity is rarely focused on. Different management methods will have a profound impact on the diversity of forest structure by decreasing or increasing individual tree size differentiation, changing the 
distribution pattern of trees or reducing the tree species. How to evaluate the management activities to improve the diversity of stand structure is particularly important. The results of the simulated thinning of different intensities and method showed that the structural diversity index was sensitive to management events. That is different management methods will produce different results, and the greater the intensity of artificial management or disturbance, the greater sensitivity of the structural diversity index to account for changes in forest structure diversity. Management to speed the development of a forest stand to a more diverse, natural condition has become an international trend (e.g., Kuuluvainen,2002). Tree size, distributional pattern, and species composition are the primary structural properties considered in forest management (Kint et al., 2000; Kint, 2005). Some management method has begun to o focus on improving the diversity of forest structure. Such as Near-natural forest management (NNFM) which aims to develop a stand structure like the original forest. Under this method, trees of different ages, species and sizes are distributed in the same stand and this method is increasingly accepted internationally because it focuses on ecological and environmental feasibility (O’Hara, 2001,2007). Another management method is the structure-based forest management (SBFM) (Hui et al. 2007; Li et al. 2014) which focus on improving the stand structure diversity by using the neighborhood-based structural parameters. This method has been applied to some successful experiments and demonstrations in Korean pine broad-leaved forest (Zhao, et al., 2013; Li, et al., 2014) and Quercus aliena broad-leaved forest in China (Bai, 2016). Therefore, this feature of high sensitivity of newly stand structural diversity is important to evaluate management activities and can be applied to guide specific forest management activities and to evaluate the effects of forest management on forest structure.

In the analysis, tree $\mathrm{DBH}$ was used as a comparative indicator of tree size differentiation because DBH data are easy to obtain and accurate. However, crown dimensions or tree height can also be used as comparative indicators of size differentiation. 
429 This reflects the flexibility of the new structural diversity index. Another significant 430 practical advantage of the structural diversity index is that tree coordinates are not required.

431 The value of $S^{\prime}{ }_{D}$ can be assessed as part of a routine forest survey at almost no additional 432 cost. In terms of a structural unit, after selecting the reference tree, its $n$ nearest neighbors 433 and their species need to be identified, possibly in the field. If tree coordinates are not 434 assessed, we can also use the same method to collect the diversity data, and additional 435 measurements are not needed.

\section{Conclusions}

437 According to the above analysis, the new index has at least four advantages compared 438 with other indexes. Firstly, it provides minimum and maximum values for different structural unit types in forests so that a unified comparative basis for evaluating forest structure diversity is achieved. Secondly, the new method takes three factors simultaneously into account to evaluate forest structure diversity, i.e. distribution pattern of trees, size differences and tree species. Researchers can choose different indicators of size differentiation according to their focus. Thirdly, the new index is sensitive to changes in stand structure to evaluate the impact of management activities on the diversity of stand management and monitoring.

\section{Acknowledgments}

We are grateful to Prof. Arne Pommerening who provided data of Germany and Poland. We also grateful to Xiaolong Shi, Anmin Li and other colleagues who participated in the field survey. 
This work was supported by National Natural Science Foundation of China (31670640),

455 the Basic Research Fund of CAF(CAFYBB2020ZB002-1) and the Basic Research Fund

456 of RIF (Grant No. RIF2014-10).

457 Availability of data and materials

458 The datasets used and/or analyzed during the current study are available from the

459 corresponding author upon reasonable request.

460 Authors' contributions

461 ZZ and HG drafted the manuscript, ZG drew the figures, and all authors contributed to

462 the writing of the manuscript. All authors read and approved the final manuscript.

463 Ethics approval and consent to participate

$464 \quad$ Not applicable.

465 Consent for publication

466 Not applicable.

467 Competing interests

468 The authors declare that they have no competing interests.

469 Author details

$470{ }^{1}$ Research Institute of Forestry, Chinese Academy of Forestry, Key Laboratory of Tree

471 Breeding and Cultivation of National Forestry and Grassland Administration,

472 Beijing,China 100091; ${ }^{2}$ Key Laboratory of Secondary Forest Cultivation Gansu Province;

473 Xiaolongshan Research Institute of Forestry of Gansu Province, Tianshui Gansu,741020,

474 China)

475

476 Reference

477 Aguirre O, Hui G, von Gadow K, et al. 2003. An analysis of spatial forest structure using 


$$
\text { neighbourhood-based }
$$

variables.

Forest

Ecol.

Manage.,183(1-3):137-145. https://doi.org/10.1016/s0378-1127(03)00102-6

Albert M, Gadow K. 1998. Assessing biodiversity with new neighborhood-based parameters $[\mathrm{C}] / /$ Proceedings of the International Conference on Data Management and Modelling Using Remote Sensing and GIS for Tropical Forest Land Inventory. Jakarta, Indonesia.

Bachofen, H., Zingg, A., 2001. Effectiveness of structure improvement thinning on stand structure in subalpine Norway spruce (Picea abies (L.) Karst.) stands. Forest Ecol. Manage. 145, 137-149. https://doi.org/10.1016/s0378-1127(00)00581-8

Bai, C. 2016. Spatial structure parameters and the application on studying structure dynamics of natural Quercus Aliena var. Acuteserrata forest. Ph.D. dissertation. Chinese Academy of Forestry. Beijing.

Barnett, J.L., How, R.A., Humphreys,W.F., 1978. The use of habitat components by small mammals in eastern Australia. Aust. J. Ecol. 3, 277-285. https://doi.org/10.1111/j.1442-9993.1978.tb01177.x

Bonet, J.A., de-Miguel, S., Martinez, de Aragon, J., Pukkala, T., Palahi, M., 2012.Immediate effect of thinning on the yield of Lactarius group deliciosus in Pinuspinaster forests in northeastern Spain. Forest Ecol. Manage. 265, 211-217.

Buongiorno, J., Dahir, S., Lu, H., Lin, C., 1994. Tree size diversity and economic returns in uneven-aged forest stands. Forest Sci.40, 83-103.

Cassidy, M., Palmer, G., Glencross, K., Nichols, J.D., Smith, R.G.B., 2012. Intensity of thinning affects $\log$ size and value in Eucalyptus pilularis. Forest Ecol. Manage. 264, 220-227.

Dewalt, S.J., Maliakal, S.K., Denslow, J.S., 2003. Changes in vegetation structure and composition along a tropical forest chrono sequence: implications for wildlife. Forest Ecol. Manage., 182, 139-151. https://doi.org/10.1016/s0378-1127(03)00029-x

Ferris R, Humphrey J W. 1999. A review of potential biodiversity indicators for application in British forests. Forestry, 72(4): 313-328. https://doi.org/10.1093/forestry/72.4.313

Franklin, J.F., Spies, T.A., Van Pelt, R., Carey, A.B., Thornburgh,D.A., Berg, D.R., Lindenmayer, D.B., Harmon, M.E., Keeton, W.S., Shaw, D.C., Bible, K., Chen, J., 2002. Disturbances and structural development of natural forest ecosystems with silvicultural implications, using Douglas-Fir forests as an example. Forest Ecol. Manage. 155, 399-423. https://doi.org/10.1016/s03781127(01)00575-8 
Füldner, K. 1995 Strukturbeschreibung von Buchen-Edellaubholz-Mischwäldern. (Describing forest structures in mixed beech-ash-maple-sycamore stands.) Ph.D. dissertation, Faculty of Forestry, University of Göttingen, Cuvillier Verlag Göttingen, 163 pp.

Gadow, K. v., Tremer, N. and Mylius, A., 2005. Datengewinnung für die Forsteinrichtungsforschung. Forst u. Holz 61 (2): 60-65.

Gadow, K.v., 1993. Zur Bestandesbeschreibung in der Forsteinrichtung. [New variables for describing stands of trees. Forst u. Holz 48, 602-606.

Gadow, K.v., 1999.Waldstruktur und Diversität [Forest structure and diversity].Allg. Forst- u. J. -Zeitung $170,117-122$.

Gadow, K.V., Hui, G.Y., Albert, M. 1998. Das Winkelmab-ein Strukturparameter zur Beschreibung der Individualverteilung inWaldbeständen. Centralblatt für das gesamte Forstwesen 115: 1-10.

Gavrikov V, Stoyan D. 1995. The use of marked point processes in ecological and environmental forest studies. Environ Ecol. Stat., 2(4):331-344. https://doi.org/10.1007/bf00569362

Gove, J.H., Patil, G.P., Taillie, C., 1995. A mathematical programming model for maintaining structural diversity in uneven-aged forest stands with implications to other formulations. Ecol. Model. 79, 11-19. https://doi.org/10.1016/0304-3800(94)00044-i

Graz F P. 2004. The behaviour of the species mingling index Msp in relation to species dominance and dispersion. Eur. J Forest Res, 123(1): 87-92. https://doi.org/10.1007/s10342-004-0016-8

Holdridge L R. 1967. Life zone ecology[]. Life zone ecology., (rev. ed.)).

Holland, D. N., Lilieholm, R. J., Roberts, D. W., \& Gilless, J. K. 1994. Economic trade-offs of managing forests for timber production and vegetative diversity. Can. J Forest Res., 24(6):1260-1265. https://doi.org/10.1139/x94-165

Holland, D. N., Lilieholm, R. J., Roberts, D. W., \& Gilless, J. K. 1994. Economic trade-offs of managing forests for timber production and vegetative diversity. Can. J Forest Res., 24(6):1260-1265. https://doi.org/10.1139/x94-165

Hui, G. Y., Albert, M. Gadow, K. v. 1998. Das Umgebungsmaß als Parameter zur Nachbildung von Bestandesstrukturen. Forstw. Cbl. 117(1):258-266.

Hui, G. Y., Gadow, K. v. 2002. Das Winkelmass-Theoretische Überlegungen zum optimalen Standardwinkel[J]. Allgemeine Forst u. Jagdzeitung,173(9):1-10.

Hui G, Zhang G, Zhao Z, et al. 2019. Methods of Forest Structure Research: a ReviewJ]. Current 
538 Hui, G. Y., Albert M., 2004. Stichprobensimulationen zur Schätzung nachbarschaftsbezogener Strukturparameter in Waldbeständen (Simulation studies for estimating neighborhood-based structural parameters in forest stands). Allgemeine Forst und Jagdzeitung 175(10/11): 199-209.

Hui, G., \& Pommerening, A. 2014. Analysing tree species and size diversity patterns in multi-species

Hui, G., Zhao, X., Zhao, Z., \& von Gadow, K. 2011. Evaluating tree species spatial diversity based on

$$
\text { relationships. }
$$

Forest

Science, 57(4), 292-300. https://doi.org/10.1093/forestscience/57.4.292

Hui, G.Y., Albert, M., Gadow, K.V. 1998. Das Umgebungsmab als parameter zur Nachbildung von bestandesstrukturen. Forstwissenschaft Centralblatt 117: 258-266.

Illian, J., Penttinen, A., Stoyan, H., Stoyan, D., 2008. Statistical Analysis and Modelling of Spatial Point Patterns. John Wiley \& Sons, Chichester, 534p.

Jaehne S, Dohrenbusch A. 1997. Ein Verfahren zur Beurteilung der BestandesdiversitätA method to evaluate forest stand diversity. Forstwissenschaftliches Centralblatt, 116(1-6): 333-345.

Kempka C, Gadow K. 1998. Eine Strukturanalyse im Naturwald von Knysna. Forstarchiv, 69(6): 235239.

Khinchin, A. I. 1957. Mathematical foundations of information theory. Dover Publications, New York. Kint V, Van Meirvenne M, Nachtergale L, et al. 2003. Spatial methods for quantifying forest stand structure development: a comparison between nearest-neighbor indices and variogram analysis. Forest science, 49(1): 36-49. ttps://doi.org/10.1093/forestscience/49.1.36

Kint, V., 2005. Structural development in ageing temperate Scots pine stands. Forest Ecol. Manage. 214, $237-250$.

Kint, V., Lust, N., Ferris, R., Olsthoorn, A.F.M., 2000. Quantification of forest stand structure applied to Scots pine (Pinus sylvestris L) forests. Investigación Agraria: Sistemasy Recursos Forestales Fuera de serie 1, 147-163.

Kuuluvainen, T., Penttinen, A., Leinonen, K. \& Nygren, M. 1996. Statistical opportunities for comparing stand structural heterogeneity in managed and primeval forests: an example from boreal spruce forests in Southern Finland. Silva Fennica, 30: 315-328. 
568 Kuuluvainen, T., 2002. Natural variability of forests as a reference for restoring and managing biological 569 diversity in boreal Fennoscandia. Silva Fennica 36, 97-125.

570 Lei X D, Tang S Z. 2002. Indicators of structural diversity within stand: review. Scientia Silvae Sinicae, 38(3):146-141. https://10.3321/j.issn:1001-7488.2002.03.025

Lei, X., Wang, W., \& Peng, C. 2009. Relationships between stand growth and structural diversity in spruce-dominated forests in New Brunswick, Canada. Can. J Forest Res., 39(10): 1835-1847. https://doi.org/10.1139/x09-089

Li Y, Hui G, Zhao Z, et al. 2012. The bivariate distribution characteristics of spatial structure in natural Korean pine broad-leaved forest. Journal of Vege. Sci., 23(6): 1180-1190. https://doi.org/10.1111/j.1654-1103.2012.01431.x

Li Y, Hui G, Zhao Z, et al. 2014. Spatial structural characteristics of three hardwood species in Korean pine broad-leaved forest-Validating the bivariate distribution of structural parameters from the point of tree population. Forest Ecol. Manage, 314: 17-25. https://doi.org/10.1016/j.foreco.2013.11.012

Mäkinen, H., Isomäki, A., 2004. Thinning intensity and long-term changes in increment and stem form of Scots pine trees. Forest Ecol. Manage. 203, 21-34

Neumann M, Starlinger F. 2001. The significance of different indices for stand structure and diversity in forests. Forest Ecol. Manage., 145(1-2): 91-106. https://doi.org/10.1016/s03781127(00)00577-6

O'Hara K L. 1998. Silviculture for structural diversity: a new look at multi aged systems. J. Forestry, 96(7): 4-10. https://doi.org/10.1093/jof/96.7.4a

O’Hara, K.L., 2001. The silviculture of transformation - a commentary. Forest Ecol. Manage. 151, 81- 
O'Hara, K.L., 2007. Integrating dynamics into management of complex forests: seeking balance in an unbalanced world. In: Conference: Complex Stand Structures and Associated Dynamics: Measurement Indices and Modelling Approaches, Sault Ste. Marie, Ontario, Canada, p. 20.

Pommerening A, Murphy S T. 2004. A review of the history, definitions and methods of continuous cover forestry with special attention to afforestation and restocking. Forestry, 77(1): 27-44. https://doi.org/10.1093/forestry/77.1.27

Pommerening A. 2006. Evaluating structural indices by reversing forest structural analysis. Forest Ecol. Manage., 224(3): 266-277. https://doi.org/10.1016/j.foreco.2005.12.039

Pommerening, A., 2002. Approaches to quantifying forest structures. Forestry,75, 305-324. https://doi.org/10.1093/forestry/75.3.305

Pommerening, A., Särkkä, A., 2013. What mark variograms tell about spatial plant interactions. Ecol. Mod. 251, 64-72. https://doi.org/10.1016/j.ecolmodel.2012.12.009

Ripley B D, Kelly F P. Markov point processes. Journal of the London Mathematical Society, 1977, 2(1): 188-192. https://doi.org/10.1112/jlms/s2-15.1.188

Ripley B D. 1977. Modelling spatial patterns. Journal of the Royal Statistical Society. Series B (Methodological), 172-212.

Spies, T.A. 1998. Forest structure: a key to the ecosystem. Northwest Science 72: 34-36.

617 Spies, T.A., Franklin, J.F., 1991. The structure of natural young, mature, and old-growth Douglas-Fir 618 forests in Oregon and Washington. In: Aubry, K.B., Brookes, M.H., Agee, J.K., Anthony, R.G., Franklin, J.F. (Eds.), Wildlife and Vegetation of Unmanaged Douglas-Fir Forests. USDA Forest Service, Portland, Oregon, pp. 91-109.

Stoyan D, Penttinen A. 2000. Recent applications of point process methods in forestry statistics. Stat. Sci., 61-78. https://www.jstor.org/stable/2676677 Lodgepole Pine forest: 10-year results after thinning. Ecol. Soc. Am. 11, 1151-1173. 
https://doi.org/10.2307/3061019

Svensson, J.S., Jeglum, J.K., 2001. Structure and dynamics of an undisturbed old-growth Norway spruce forest on the rising Bothnian coastline. Forest Ecol. Manage. 151, 67-79. https://doi.org/10.1016/s0378-1127(00)00697-6

Uria-Diez J, Pommerening A. Crown plasticity in Scots pine (Pinus sylvestris L.) as a strategy of adaptation to competition and environmental factors. Ecol. Mod., 2017, 356: 117-126. https://doi.org/10.1016/j.ecolmodel.2017.03.018

Valbuena R, Packalén P, Martı S, et al. 2012.Diversity and equitability ordering profiles applied to study forest structure.Forest Ecol. Manage., 276:185-195. https://doi.org/10.1016/j.foreco.2012.03.036

Van Den Meersschaut, D., Vandekerkhove, K., 1998. Development of a stand-scale forest biodiversity index based on the State Forest Inventory. In: Hansen, M., Burk, T. (Eds.), Integrated Tools for Natural Resources Inventories in the 21st Century. USDA, Boise, Idaho, pp. 340-349.

Volin L and Buomgiorno J. 1996.Effect of alternative management regimes on forest stand structure, species composition and income: a model for the Italian Dolomites. For. Ecol. Mnage. 87: 107125. https://doi.org/10.1016/s0378-1127(96)03828-5

Von Gadow K, Hui G Y. 2002. Characterizing forest spatial structure and diversity[C]//Sustainable forestry in temperate regions. Proc. SUFOR Int. Workshop, Lund, Sweden. 20-30.

Wang, H., Zhang, G., Hui, G., Li, Y., Hu, Y., \& Zhao, Z. 2016. The influence of sampling unit size and spatial arrangement patterns on neighborhood-based spatial structure analyses of forest stands. Forest Syst., 25(1), e056.

Wiegand T, Moloney KA. Handbook of spatial point-pattern analysis in ecology: CRC Press; 2013.

Zenner, E.K., 2000. Do residual trees increase structural complexity in Pacific Northwest coniferous forests? Ecol. Appl. 10, 800-810. https://doi.org/10.2307/2641046

Zhang G., Hui G., Zhang G., et al. 2019. Telescope method for characterizing the spatial structure of a pine -oak mixed forest in the Xiaolong Mountains, China. Scand J Forest Res, 34(6): 1-12. https://doi.org/10.1080/02827581.2019.1680729

Zhang J. C., Chen L., Guo Q. S., Bai, X. L., Jiang Y. X., 1999. Research on the change trend of dominant tree population distribution patterns during development process of climax forest communities. Acta. Phyt. Sin., 23(3): 256-268.

Zhang, L. J., Hu, Y. B., Zhao, Z. H., Song, C. Z. 2015. Spatial structure diversity of platycladus orientalis 

plantation in Beijing Jiulong Mountain. Chinese J. Ecol., 34(1):60-69.

658 Zhao Z. Hui G., Hu, Y., et al. 2013. Application of structure-based forest management in broadleaved 659 Korean Pine mixed forest. For Res, 26(4):467-472. https://doi.org/10.3969/j.issn.10011498.2013.04.012

661 Zhao Z, Hui G, Hu Y, et al. 2014.Testing the significance of different tree spatial distribution patterns 662 based on the uniform angle index. Can. J Forest Res., 44(11): 1419-1425. https://doi.org/10.1139/cjfr-2014-0192

664 Zhao Z, Liu W, Shi X, et al. 2015. Structure Dynamic of Quercus aliena var. acuteserrata Natural Forest on 665 Xiaolongshan. For Res, 28(6): 759-766.

666 Zin M T. 2005. Developing a scientific basis for sustainable management of tropical forest watersheds: 667 case studies from Myanmar. Universitätsverlag Göttingen. https://doi.org/10.17875/gup2005- 


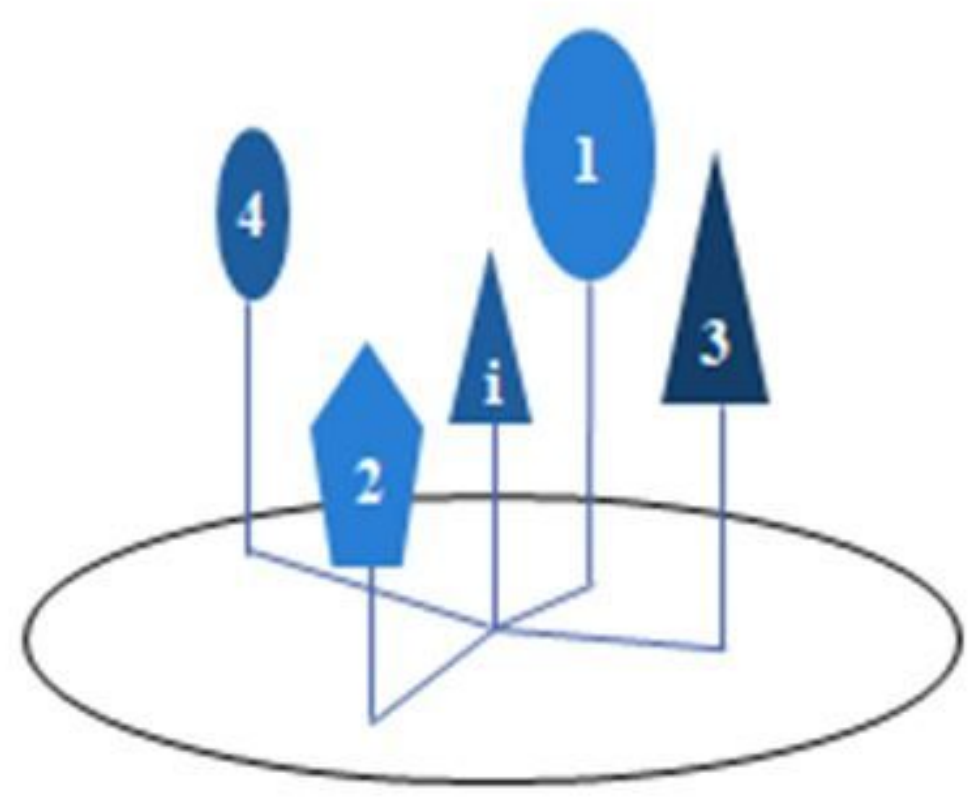

Figure 1

Stand spatial structural unit In the graph, $i$ is the reference tree, and 1, 2, 3 and 4 are the four nearest neighbor trees.
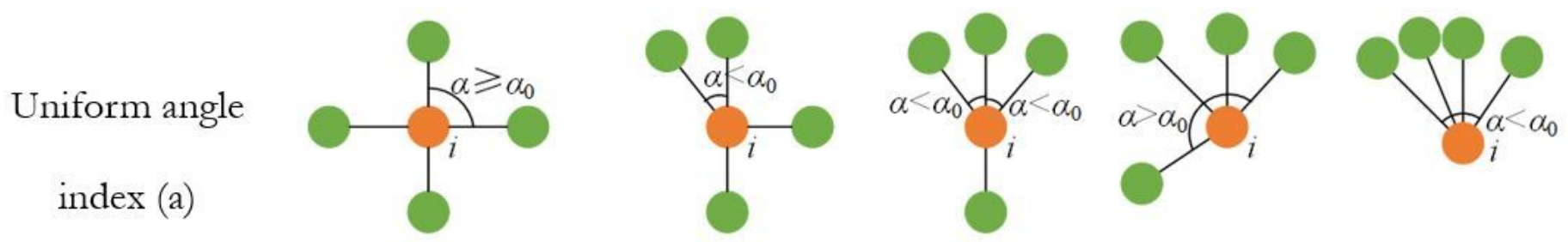

$$
W_{i}=0.00
$$

$W_{i}=0.25$

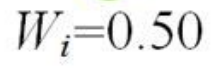

$W_{i}=0.75$

$W_{i}=1.00$
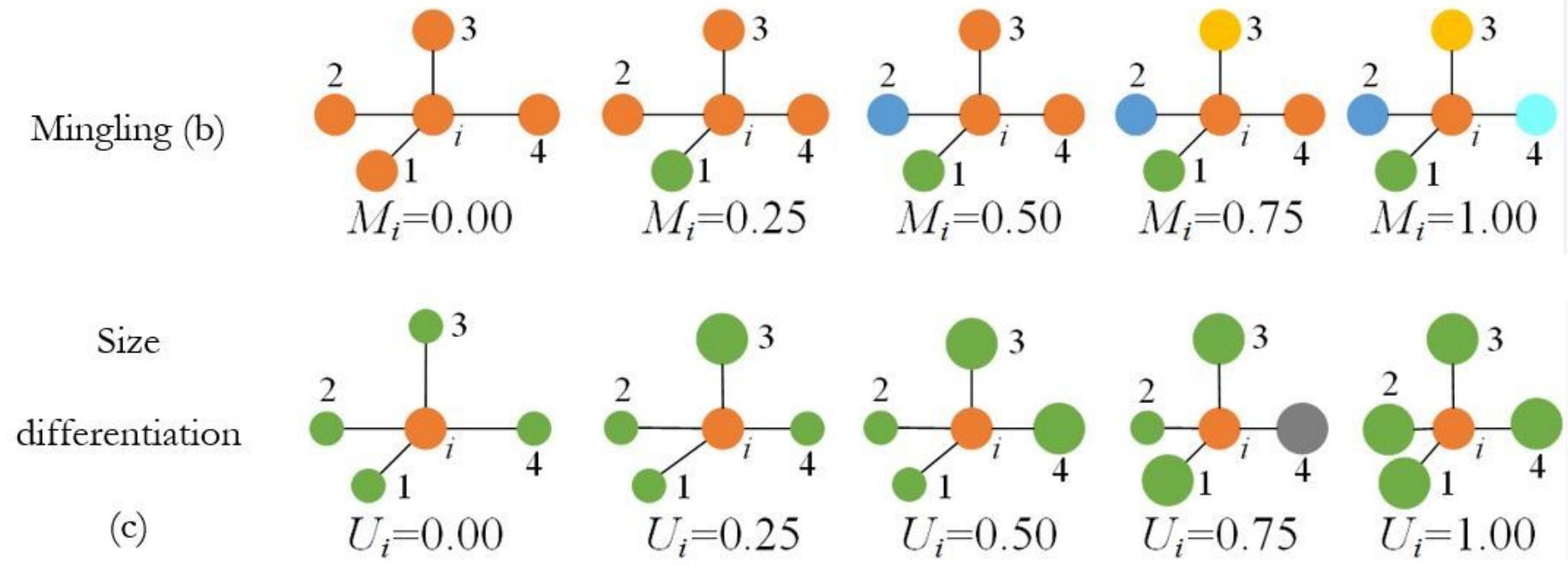


\section{Figure 2}

The values of the stand spatial structural parameters Uniform angle index (a) from left to right, the diagrams depict the distribution patterns of very regular, regular, random, irregular and very irregular neighborhoods. Black and gray dots denote different tree species in Mingling (b). From left to right, there are $0,1,2,3$ and 4 trees belonging to the same species in the structural unit. Circles denote the size of trees in size differentiation (c). From left to right, 0, 1, 2, 3 and 4 trees are larger than the reference tree in the structural unit.

\section{Supplementary Files}

This is a list of supplementary files associated with this preprint. Click to download.

- Appendix.docx 